\title{
Joe Louis contra Max Schmeling e a nova ideologia da democracia racial nos Estados Unidos*
}

Jessica Graham**

Este artigo investiga as mudanças no ideário sobre raça e identidade nacional nos Estados Unidos, durante os anos 1930, através da análise da reação do público ao pugilista negro Joe Louis. Especificamente, o artigo focaliza duas lutas entre Louis e o pugilista negro Max Schmeling, ocorridas em 1936 e 1938, argumentando que o eventual símbolo da democracia que Louis encarnaria refletia a emergência de um nacionalismo.

Palavras-chave: Estados Unidos - Identidade Nacional - Raça

Joe Louis vs. Max Schmeling and the new ideology of racial democracy in the USA

This article assesses changing ideals about race and US national identity during the 1930 s through an analysis of public reaction to black pugilist Joe Louis. Specifically, the article focuses on Louis' 1936 and 1938 fights with German boxer Max Schmeling, arguing that Louis' eventual symbolism as US democracy incarnate reflected an emergent racially inclusive nationalism in mainstream society.

Keywords: USA - National Identity - Race

\footnotetext{
* Artigo recebido em março de 2008 e aprovado para publicação em maio de 2008. Este texto foi elaborado a partir de Hitler's Nazism Sport, and Joe Louis: Racism vs. Pseudo-Democracy in América. Dissertação de Mestrado Cornell University, 2000. Os professores no comitê da dissertação foram Robert Harris Jr. (orientador) e James Turner.

** Doutoranda do Programa de Pós-Graduação da Universidade de Chicago.

E-mail: jlg@uchicago.edu.
} 
Joe Louis contre Max Schmeling et la nouvelle idéologie de la démocratie raciale aux Etats-Unis

Cet article évalue les changements d'idéaux relatifs à la question de la race et de l'identité nationale aux USA durant les années 30, et ce à travers une analyse des réactions du public vis à vis du boxeur noir Joe Louis. L'article cible particuliérement les combats de Louis en 1936 et 1938 contre le boxeur allemand Max Schmeling montrant que l'éventuel symbole de démocratie aux USA incarné par Louis reflète l'émergence d'un nationalisme racialement inclusif dans la société traditionelle.

Mots-clés: USA - Identité Nationale - Race

\section{Introdução}

Antes que Adolf Hitler invadisse a Polônia, o nazismo já provocava mudanças importantes do outro lado do Atlântico. Nos Estados Unidos, o ambiente ideológico foi especialmente afetado, com impacto nas representações da identidade nacional, especialmente no que dizia respeito à questão da inclusão racial. Este artigo analisa a dinâmica dessas representações antes da Segunda Guerra Mundial, através de uma investigação da reação pública ao famoso boxeador negro Joe Louis. Ele examina o impacto que o nazismo teve no esporte, especificamente na articulação dos conceitos de raça e pátria nos Estados Unidos, e demonstra que o nazismo foi um de vários fatores que impulsionaram o início do desmantelamento das ideologias convencionais sobre a exclusão racial no país. Ironicamente, enquanto o racismo social, econômico, político e cultural mantinha seu curso na sociedade norte-americana, uma mudança ocorria no pensamento dominante no sentido de desvalorizar as idéias nacionalistas da exclusão racial e introduzir uma mentalidade democrática cuja referência fundamental era inclusão; em outras palavras, o paradigma da democracia racial. O primeiro argumento oferecido aqui é que a trajetória de Joe Louis, de negro nos Estados Unidos para negro americano, acompanhou a transição geral da ideologia/identidade nacional excludente para o seu oposto: a democracia racial. O texto também demonstra que o apoio público a Joe Louis no fim da década de 1930 ajudou a sustentar a contradição e o equilíbrio precário entre uma sociedade racista e a ideologia de democracia racial nascente no país. 


\section{Oboxe, a masculinidade e o nacionalismo racista nos Estados Unidos}

O boxe sempre foi um esporte a destacar as referências de masculinidade e raça no nacionalismo norte-americano. ${ }^{1}$ Desde o século XIX, o boxe peso pesado e o seu campeão têm sido considerados ícones de masculinidade e coragem, e nos anos entre a Guerra Civil e a Primeira Guerra Mundial, a chamada "Época da Corporação", ampliou-se esse sentido do esporte e sua popularidade na sociedade norte-americana. A Época da Corporação, ou o predomínio marcante de grandes empresas, assinalou o declínio do homem jeffersoniano, independente e auto-suficiente. ${ }^{2}$ Os homens da classe média viram diluir-se a individualidade que tinha definido a sua masculinidade na onda de modernização e industrialização. Assim, no contexto de uma suposta "crise da masculinidade", ${ }^{3}$ no início do século XX, assistiu-se ao aumento da obsessão por qualquer coisa relacionada à virilidade. Aliás, enquanto os Estados Unidos permanecessem um poder global, o simbolismo do título peso pesado de masculinidade e bravura também refletiria a força e a superioridade nacional, e os norte-americanos continuariam a desejar gerar o herói mais masculino e poderoso do mundo para corroborar a invencibilidade e a nova posição global do país. ${ }^{4}$

O desejo norte-americano de assegurar o título peso pesado não significava que afro-americanos também teriam o direito de representar o poder e a masculinidade nacional. Ao contrário, nos Estados Unidos, a força nacional e a superioridade da raça branca eram consideradas equivalentes, como revela a história do pugilista Jack Johnson, conforme indicaremos adiante. Por isso, quando Louis, um pugilista negro, entrou no ringue para lutar contra um oponente branco, crenças da superioridade da raça branca e, ao mesmo tempo,

\footnotetext{
${ }^{1}$ Embora Gail Bederman demonstre que o uso do termo masculinidade tem uma história complexa, neste artigo masculinidade é definida como força, vigor, virilidade, potência e coragem, ou seja, as características que a sociedade espera de um homem ideal. Ver Gail Bederman, Manliness and Civilization: A Cultural History of Gender and Race in the United States, 1880-1917, Chicago, University of Chicago Press, 1995.

${ }^{2}$ Jeffrey T. Sammons, Beyond the Ring: The Role of Boxing in American Society, Urbana e Chicago, University of Illinois Press, 1988, p. 13.

${ }^{3}$ Conforme Bederman, a existência de uma verdadeira "crise da masculinidade" entre os homens da classe média no início do século XX é objeto de debate pelos historiadores. Ela argumenta que muitos fatores se associaram para alterar o sentido de manhood (qualquer coisa, atividade, característica etc. ligada a ser um homem) nessa época, mas não seria apropriado falar em uma crise. Ao contrário, ela defende que valores de gênero sempre mudam, e que gênero é um "processo ideológico" dinâmico. Ver Bederman, Manliness and Civilization, p. $10-20$.

${ }^{4}$ Esse sentido nacionalista associado ao título limitou-se à categoria peso pesado. Ver Sammons, Beyond the Ring, p. 31-44.
} 
dos Estados Unidos foram desafiadas, mesmo sendo o lutador negro norteamericano e o branco de outro país. ${ }^{5}$ Até Joe Louis, os esforços para manter o campeão norte-americano sempre foram ofuscados pelos esforços voltados para proteger a noção da superioridade branca.

A maioria dos campeões pesos pesados queria que o título afirmasse a superioridade da masculinidade branca e do nacionalismo branco, e eles se recusaram a lutar contra pugilistas negros. O popular peso pesado norteamericano John L. Sullivan foi direto e objetivo ao declarar: "Não luto contra os 'niggers". ${ }^{6}$ Jim Jeffries, reverenciado campeão norte-americano, seguiu o exemplo de Sullivan, dizendo que "quando não houver mais brancos para lutar, vou deixar o boxe... Estou determinado a não dar oportunidade de perder o campeonato para um negro". ${ }^{7}$ Mas em 1908, o pugilista negro norte-americano Jack Johnson finalmente teve a oportunidade de disputar a coroa dos pesos pesados contra Tommy Burns, o campeão mundial canadense. ${ }^{8}$ No dia 26 de dezembro de 1908, Jack Johnson derrotou Tommy Burns por nocaute no $14^{\circ}$ round e assim conquistou a coroa. A maioria do público norte-americano concordou com os sentimentos de Jack London, o romancista e jornalista famoso: "(Burns) é um homem branco e eu também. Naturalmente eu queria ver o branco vencer". 9

\footnotetext{
${ }^{5}$ Idem, p. 31.

${ }^{6}$ Kansas City American Citizen, 26 de julho de 1889. (Tradução da autora.) Sullivan foi o primeiro campeão moderno (entre 1882-1892) a lutar com luvas. A recusa de Sullivan e outros pugilistas brancos de lutar contra negros representou uma mudança histórica no boxe. Embora pugilistas negros sempre enfrentassem racismo no esporte, alguns pesos pesados negros tiveram oportunidade de conquistar a coroa nos séculos XVIII e XIX, como ocorreu com Tom Molineaux e Bill Richmond. A modalidade peso leve, que não estava associada à mesma referência nacionalista e masculina dos pesos pesados, continuou a ter campeões negros. Ver Sammons, Beyond the Ring, p. 32-33.

${ }^{7}$ Ver Bederman, Manliness and Civilization, p. 1. Jeffries foi campeão entre 1899-1905. As palavras originais de Jeffries foram: "When there are no white men left to fight, I will quit the business... I am determined not to take a chance of losing the championship to a negro". (Tradução da autora.)

${ }^{8}$ Burns decidiu opor-se à tradição de rejeitar lutadores negros por várias razões. Desde a aposentadoria de Jim Jeffries, o interesse dos norte-americanos pelo boxe refluiu bastante e Burns, um lutador menos empolgante, não atraía muitos espectadores, e o esporte perdia dinheiro. Muitos jornalistas esportivos começaram a insistir que Burns enfrentasse um negro para ressuscitar o esporte. No final, a pressão da mídia, de Jack Johnson (que tinha perseguido e desafiado Burns por muito tempo) e de lucros muito baixos levaram Burns a concordar em lutar contra Johnson. Sammons, Beyond the Ring, p. 34-35 e 57.

${ }^{9}$ Ver Frederic Cople Jaher, "White America Views Jack Johnson, Joe Louis, and Muhammed Ali”, Donald Spivey (organizador), Sport in America: New Historical Perspectives, Westport, CT, Greenwood Press, 1985, p. 148.
} 
Embora Jack Johnson tivesse conquistado o campeonato para os Estados Unidos, norte-americanos brancos não se identificaram com o campeão nem manifestaram qualquer solidariedade nacionalista. O público lançou uma campanha para convencer Jim Jeffries a voltar ao boxe com o objetivo de vencer Jack Johnson e recuperar o título para a raça branca. Quando Jeffries decidiu lutar contra Johnson, confessou que tinha voltado "por causa do pedido do público, que me forçou a deixar a aposentadoria. Percebo bem o que foi depositado em mim, e não vou decepcionar... A porção da raça branca que conta comigo para defender a supremacia atlética pode ficar tranqüila". ${ }^{10}$

O combate de Jack Johnson contra Jim Jeffries foi um evento importantíssimo nos Estados Unidos. O vencedor seria considerado o campeão legítimo, mais do que o vencedor do combate contra Burns. Ao contrário de Burns, Jeffries era uma celebridade norte-americana admirada e um homem julgado merecedor da caracterização feita por Jack London de ser "o representante eleito da raça branca". ${ }^{11}$ A luta de Johnson-Jeffries ocorreu em Reno, Nevada (EUA), no dia 4 de julho de 1910, e foi o assunto principal do país inteiro. ${ }^{12} \mathrm{O}$ combate foi discutido em quase todos os jornais do país e na mídia internacional. O jornal Los Angeles Times publicou um artigo característico, informando a seus leitores que "todo o mundo civilizado" aguardava a luta na qual Jim Jeffries iria "retornar ao ringue para resgatar o campeonato da raça negra". ${ }^{13} \mathrm{O}$ Chattanooga Times escreveu: "Caso a gente confesse ou não... o interesse da maioria dos noventa milhões de pessoas hoje nos Estados Unidos está focado em Reno". ${ }^{14}$

\footnotetext{
${ }^{10}$ Sammons, Beyond the Ring, p. 37. As palavras originais de Jeffries foram: "(I fight) at the request of the public which forced me out of retirement. I realize full well just what depends on me, and I am not going to disappoint... That portion of the white race that has been looking to me to defend its athletic supremacy may feel assured". (Tradução da autora.)

${ }^{11}$ Ver Jaher, "White America Views Jack Johnson, Joe Louis, and Muhammed Ali”, p. 148149.

${ }^{12}$ Idem, p. 150.

${ }^{13}$ Idem. O artigo intitula-se: "All the Givilized World Sits up and Takes Notice While Pugilistic Gladiators Prepare for Battle". Embaixo de uma foto de Jeffries, lê-se "James J. Jeffries, the Undefeated, who has re-entered the ring to rescue the championship from the negro race". (Tradução da autora.)

${ }^{14}$ Ver Al-Tony Gilmore, Bad Nigger! The National Impact of Jack Johnson, Nova York e Londres, Kennikat Press, 1974, p. 39. Chattanooga fica no estado de Tennessee, no sul do país. $\mathrm{O}$ artigo afirmava: "Whether or not we admit it, the interest of the majority of the ninetyodd millions of people in these United States is centered on Reno today". (Tradução da autora.)
} 
Antes das entradas de Johnson e Jeffries, a banda tocou uma música racista qualificada como "patriótica" por alguns jornais, traduzindo a expectativa da platéia de assistir à derrota de Johnson. ${ }^{15}$ Infelizmente para os brancos que acreditaram tanto na sua "grande esperança branca", Jeffries foi incapaz de vencer seu adversário. Nos 14 rounds, Johnson fez troça, zombou, riu do seu oponente e, finalmente, o nocauteou no $15^{\circ}$ assalto. A platéia ficou chocada, e pelo menos um espectador, Tim Sullivan, senador de Nova Iorque, desmaiou. O senador lamentou depois: "Como muitos outros, vim a Reno esperando que a raça branca triunfasse de novo sobre a raça negra. $\mathrm{O}$ destino não quis assim". ${ }^{16} \mathrm{O}$ senador exprimiu a frustração e decepção da população branca, que reagiu ao resultado da luta com violência contra negros por todo o país. Esses distúrbios raciais foram os piores que aconteceriam no país até o assassinato de Dr. Martin Luther King, Jr. ${ }^{17}$

Os clamores brancos em favor da limitação da circulação de filmes de boxe por razões morais, e as ações governamentais nos níveis municipal, estadual e federal no mesmo sentido, demonstraram o desejo de refutar a vitória de Johnson e seu simbolismo racial. A vice-presidente do Clube das Mulheres de Califórnia argumentou em favor da censura do filme da luta Johnson-Jeffries, descrevendo o povo negro como "uma raça infantil, que precisa de direção, instrução, e encorajamento". Ela afirmou que os brancos, "a raça superior", negava aos negros todas essas coisas quando os levaram enganosamente a acreditar que um campeão negro fosse significativo para a raça. ${ }^{18}$ O governador do Texas também se posicionou contra o filme, afirmando que não queria exibir uma demonstração "da supremacia física de um negro sobre um branco". ${ }^{19}$ No final, pelo menos 15 estados, Washington D.C., Inglaterra e África do Sul proibiram o filme da luta de Johnson contra Jeffries. Em julho de 1912, o Congresso aprovou uma lei proibindo o transporte de filmes do boxe no comércio entre estados. ${ }^{20}$

${ }^{15}$ William H. Wiggins, Jr., "Boxing's Sambo Twins: Racial Stereotypes in Jack Johnson and Joe Louis Newpaper [sic] Cartoons, 1908-1938”, Journal of Sport History 15.3 (1988), p. 243. O nome da música tocada era "All Coons Look Alike to Me" ou "Todos próciones parecem iguais pra mim". Prócion é um termo pejorativo e racista utilizado para referir-se a um negro.

${ }^{16}$ Ver Gilmore, Bad Nigger!, p. 42. Sullivan declarou: "Like many others I had come to Reno hoping that the white race would again triumph over the black. It was not to be". (Tradução da autora.)

${ }^{17}$ Sammons, Beyond the Ring, p. 38-40.

${ }^{18}$ Ver Gilmore, Bad Nigger!, p. 81.

${ }^{19}$ Idem, p. 77. (Tradução da autora.)

${ }^{20}$ Sammons, Beyond the Ring, p. 41-42. 
Oficiais municipais e federais continuaram a agir contra Jack Johnson enquanto o lutador manteve a coroa mundial, e chegaram a prendê-lo sob a falsa alegação de violar o Mann Act, uma lei criada para combater a escravidão e prostituição branca. A condenação, que o levou a fugir do país por muitos anos, foi em reação aos seus relacionamentos com mulheres brancas, tabu para um homem negro naquela época. Johnson não havia feito nada ilegal, só cruzado fronteiras estaduais com sua namorada branca, a quem tinha dado presentes e dinheiro, mas foi preso e estimulado pelas autoridades a fugir dos Estados Unidos. ${ }^{21}$ Johnson finalmente perdeu o título mundial, em 1915, para o pugilista norte-americano branco Jess Willard, em Havana, Cuba.

O que levou a sociedade branca dos Estados Unidos a sentir-se tão ameaçada por ter um campeão mundial norte-americano de boxe peso pesado negro? O historiador Frederic Cople Jaher argumenta que, para a maioria dos norte-americanos brancos, raça tinha prioridade sobre a nacionalidade. ${ }^{22}$ Todavia, deve ser mais exato dizer que a vida de Jack Johnson demonstra que o nacionalismo, como definido pelos brancos norte-americanos, estava relacionado estreitamente à raça. O público e o governo dos Estados Unidos consideravam o país o pináculo da civilização e da supremacia branca. $\mathrm{O}$ nacionalismo branco e a superioridade branca foram tão intimamente entrelaçados que se tornaram indiferenciados, indissociáveis. Naquela época, ser um norte-americano orgulhoso e crer na inferioridade dos negros eram termos equivalentes. Aproximadamente 20 anos depois, essa realidade continuou a existir, e o pugilista negro Joe Louis entrou no mundo do boxe peso pesado com o desafio de enfrentar esse nacionalismo racista, e também o legado de Jack Johnson.

\section{Joe Louis: negro nos Estados Unidos}

Entre a Primeira e a Segunda Guerra Mundial, o papel do boxe na sociedade norte-americana ganhou uma carga simbólica ainda maior. Muitos homens acreditaram que o envolvimento do país na primeira guerra criaria uma oportunidade rara para exibição da masculinidade e da coragem norteamericana, como nas guerras anteriores. No entanto, as batalhas foram muito diferentes daquelas do passado e dependeram bastante de tecnologia, tanques e guerra de trincheira. Os soldados voltaram da guerra apenas como veteranos, não como os heróis como era o costume. A guerra passara pela mesma trans-

${ }^{21}$ Bederman, Manliness and Civilization, p. 4.

${ }^{22}$ Jaher, "White America Views Jack Johnson, Joe Louis, and Muhammed Ali”, p. 145. 
formação e mudança de valores que a sociedade norte-americana: o sucesso individual foi sacrificado em função de avanços tecnológicos enormes. Essa mudança rápida na vida norte-americana levou muitos homens a desejar mostrar, pelo menos indiretamente, sua força individual e bravura. ${ }^{23}$ Essa atitude sobre competição "de homem", associada ao período de expansão do lazer que sucedeu à guerra, criou a chamada "Época Dourada" no esporte. Na Época Dourada, o boxe, e principalmente a categoria simbólica peso pesado, atingiu popularidade sem precedentes. ${ }^{24}$

Até que Adolf Hitler se configurasse para o público norte-americano como uma verdadeira ameaça, Joe Louis, como a maioria dos negros no país, não foi reconhecido como um norte-americano. A atitude do público branco refletia várias leis e a constituição federal, que ideologicamente e de forma literal concediam aos negros um tratamento de mais "separados" do que "iguais" na comunidade nacional. ${ }^{25}$ Assim, quando Louis pisou no ringue, o público branco não o tomou como um representante dos Estados Unidos. Em vez disso, Joe Louis era o campeão da raça negra - o rei negro cujos fãs moravam em Harlem e outras comunidades negras. Na realidade, a imprensa freqüentemente apresentava Louis tanto ou até como mais estrangeiro do que seus adversários brancos de outros países.

Quando Joe Louis estreou profissionalmente, muitos fãs de boxe de todas as raças reconhecerem seu talento, mas não achavam que um peso pesado negro pudesse alcançar sucesso. Era uma suposição comum que o mundo do boxe nunca mais suportaria outro campeão peso pesado negro depois de Jack Johnson. Até o treinador negro Jack Blackburn não queria treinar Louis de início, alegando que nunca trabalhava com os pugilistas negros porque era impossível para eles serem bem-sucedidos. ${ }^{26} \mathrm{O}$ jornalista de esporte contemporâneo Edward Van Every resumiu esse pensamento dominante com as palavras que tinha ouvido dizer um velhinho: "O Louis é muito talentoso. Que pena que seja um rapaz negro, senão alcançaria sucesso daqui a uns anos". ${ }^{27}$

\footnotetext{
${ }^{23}$ Sammons, Beyond the Ring, p. 48-49.

${ }^{24}$ Idem, p. 49-50.

${ }^{25}$ Referência à decisão da Corte Suprema no caso de Plessy contra Ferguson, em 1896, que considerou legal a segregação das raças, adotando o princípio de "separados, mas iguais". A segregação foi legal nos Estados Unidos até a decisão do caso de Brown contra Board of Education em 1954, em que a Corte Suprema estabeleceu que separado é inerentemente desigual.

${ }^{26}$ Edward Van Every, Joe Louis: Man and Super-Fighter, Nova York, Frederick A. Stokes Company, 1936, p. 59. No final, Blackburn aceitou ser treinador de Louis.

${ }^{27}$ Idem, p. 11-12. Van Every ouviu o velho dizer que Louis "is a pretty good-looking young heavy. Too bad he's a black boy, otherwise he might get somewhere in a couple of years". (Tradução da autora.)
} 
Para superar essa situação, Joe Louis fez tudo que estava ao seu alcance para evitar qualquer ligação entre ele e Jack Johnson. Enquanto Johnson mostrava-se arrogante no ringue e demonstrando prazer em vencer os seus oponentes brancos, Joe Louis apresentava-se despretensioso e humilde; enquanto Johnson se casava com mulheres brancas, Louis recusou tirar fotos com elas; enquanto Johnson era proprietário de um bar, Louis quase nunca pisava em um. Os esforços de Louis produziram resultados apenas no sentido de ganhar uma aceitação limitada como um pugilista negro hábil e respeitoso às regras que a população branca em geral via com bom grado um negro obedecer. Mas, apesar de tudo isso, muitos brancos ainda mostravam-se revoltados com a idéia de um peso pesado negro.

A primeira luta de Joe Louis contra o alemão Max Schmeling, em 1936, revelou uma atitude hostil do público norte-americano em relação a Louis, a continuação do nacionalismo excludente racialmente e a fraternidade com a doutrina nazista. Nesse primeiro combate entre os dois, Louis ainda não seria americano e Schmeling, um nazista odioso. Embora Louis fosse mais bem aceito do que qualquer outro negro peso pesado em décadas, essa luta contra Schmeling expôs o fato de que brancos norte-americanos se identificavam mais com um branco da Alemanha nazista do que com um negro norte-americano tímido, agradável e talentoso.

Quando Max Schmeling desembarcou do S.S. Bremen em Nova Iorque, em abril de 1936, para lutar contra Louis, foi recebido por uma das maiores multidões a acolher um boxeador visitante no país. Na sua descrição do alemão, um jornalista expressou a disposição do público para Schmeling, caracterizando-o como "orgulhoso inato", "bonito" e "refinado". ${ }^{28}$ Além dessa recepção cordialíssima, muitos brancos expressavam o desejo de que Schmeling fosse a próxima "grande esperança branca" e contivesse a ascensão de Louis, embora as probabilidades de Schmeling perder ficassem em torno de 10 para 1 e 5 para 1.

O próprio Adolf Hitler não incentivou o combate de Louis-Schmeling. Em sua autobiografia, Schmeling escreveu que "Hitler parecia pertubado e um tanto contrariado com o fato de que estivesse arriscando a honra alemã lutando contra um homem negro, principalmente um negro que eu aparente-

\footnotetext{
${ }^{28}$ New York Evening Journal, 22 de abril de 1936, Joe Louis Scrapbooks. Os Joe Louis Scrapbooks são o acervo de Julian Black, um empresário de Louis. O acervo contém artigos sobre Louis de jornais de toda parte do país entre 1935-1945. Os originais ficam no Arquivo do Museu Nacional de História Americana, no Smithsonian Institute.
} 
mente não tinha nenhuma chance de derrotar". ${ }^{29}$ Hitler, que se recusou a felicitar Jesse Owens, o negro norte-americano que havia ganho quatro medalhas de ouro no atletismo nos Jogos Olímpicos de 1936, em Berlim, já tinha demonstrado a convicção que o dogma racial nazista poderia ser provado, ou refutado, através do esporte. Hitler compreendeu a influência que o esporte tinha na política e temia que uma vitória de Louis abalasse a ideologia nazista.

Ao contrário de Hitler, dos judeus que boicotaram o combate e da população negra que sempre torcia fortemente por Louis, a maioria dos norte-americanos não considerou a luta em termos tão sérios. Um artigo do jornalista Henry McLemore antes do combate refletia a perspectiva da América branca sobre a luta:

Nesta sexta-feira de noite no Yankee Stadium (...) dois homens, um negro das fazendas de algodão de Alabama, e outro um alemão de Berlim com sobrancelhas grossíssimas, vão encarar-se e dar-se uns socos na cara com punhos de couro. ${ }^{30}$

Por causa do recorde e do talento impressionante de Louis, a suposição era de que venceria. Em geral, foi a qualidade técnica do próprio Louis que lhe rendeu o apoio de torcedores brancos que apostaram em sua vitória. Mas, num resultado surpreendente, Max Schmeling nocauteou Joe Louis no $12^{\circ}$ round. Durante o combate, os espectadores brancos, inclusive os que foram torcer por Joe Louis, mudaram repentinamente sua disposição. Segundo Schmeling, a platéia passou a torcer por ele desde a primeira vez em que fez Louis cair no chão brevemente:

Nunca ouvi uma explosão assim - 40.000 pessoas pularam dos seus assentos e o Yankee Stadium pareceu que ia explodir. Até esse momento, a platéia vinha apoiando Louis unanimemente e torcera cada vez que me golpeava. Nesse momento, percebi que estava havendo uma reviravolta em meu favor. ${ }^{31}$

A reportagem do jornalista Richards Vidmer no dia seguinte da luta comprova a lembrança de Schmeling: "Desde o sétimo round até o fim a platéia berrou animadamente... E a admiração da multidão virou-se para Schmeling". 32 No $8^{\circ}$ round, quando pareceu que Schmeling ia derrubar Louis, a platéia gritou: "Mate-o! Mate-o!". 33

${ }_{29}$ Max Schmeling, Max Schmeling: An Autobiography, George B. von der Lippe (tradutor), Illinois, Bonus Books, Inc., 1998, p. 111. (Tradução da autora.)

30 Salt Lake Telegram, 18 de junho de 1936, Joe Louis Scrapbooks. McLemore escreveu: "Friday night in Yankee Stadium (...) two men, one a negro from the cotton fields of Bama, the other a beetle-browed German from Berlin, will stand toe to toe and bash each other in the face with leather fists". (Tradução da autora.)

${ }^{31}$ Schmeling, Max Schmeling, p. 123.

${ }^{32}$ New York Herald Tribune, 20 de junho de 1936, Joe Louis Scrapbooks.

${ }^{33}$ Schmeling, Max Schmeling, p. 124. 
Quando Schmeling nocauteou Louis, até os brancos que perderam dinheiro apostando em Louis se disseram encantados com o resultado da luta. Conforme lembrou Schmeling, Louis quase nem tinha caído no chão quando a celebração começou:

De repente o ringue ficou cheio de gente. Várias pessoas me davam pancadinhas nas costas e me abraçavam (...) Somente com esforço enorme consegui chegar ao vestiário, pelo (...) barulho ensurdecedor. Algumas pessoas da multidão estendiam a mão como se quisessem só tocar-me, enquanto outras rasgavam minhas ataduras da mão como se fossem relíquias sagradas (...) $\mathrm{O}$ meu quarto no hotel ficou cheio de flores (...) Muitas outras continuavam a chegar no quarto e os carregadores vinham incessantemente com cestos de telegramas de parabéns. ${ }^{34}$

Essa reação dos torcedores brancos indicava o seu desejo de ver o alemão arrebatar o título do negro e, por um pequeno período e de modo imprevisto, Schmeling passou a encarnar a "grande esperança branca".

Como os espectadores brancos do combate, a imprensa também pareceu satisfeita com o resultado da luta Louis-Schmeling e mostrou-se cruel na análise da derrota de Louis. O historiador Jeffrey Sammons argumenta que a imprensa, que tinha previsto a derrota de Schmeling, provavelmente o fez para "proteger a sua própia credibilidade" na crítica a Louis. ${ }^{35}$ Mas, nas reportagens sobre a luta, a mídia revelou uma reação ao resultado do combate racialmente motivada, depreciando Louis por sua cor. O Washington Post, por exemplo, declarou que Schmeling reduziu Louis a "um negro cansado e grotesco tipo Stepin fetchit" e o Philadelphia Evening Bulletin afirmou que "não tem mais Joe Louis, somente um cansado, moleque tipo Stepinfetchit". ${ }^{36}$ Enquanto a imprensa entretinha seus leitores com imagens de Joe Louis como Stepin Fetchit bobo, Schmeling foi louvado

\footnotetext{
${ }^{34}$ Idem, p. 126-127.

${ }^{35}$ Sammons, Beyond the Ring, p. 108.

${ }^{36}$ Washington Post, 20 de junho de 1936; Philadelphia Evening Bulletin, 20 de junho de 1936, Joe Louis Scrapbooks. O Post e o Bulletin publicaram, respectivamente, "a grotesque Stepin fetchit type of tired Negro" e "No mo' Joe Louis - just a tired and Stepinfetchit sort of fella with too many rows to hoe". Traduções da autora. "Stepin fetchit" ou "Stepinfetchit" era o personagem do ator negro Lincoln Perry (1902-1985), que, embora fosse mais complicada do que parecia na realidade, encarnou o estereótipo do negro servil, bobo, estúpido e analfabeto. O artigo no Philadelphia Evening Bulletin usou expressões reconhecidas como integrantes de dialetos negros e mencionou o trabalho de fazenda em referência a Louis. Os dois eram estereótipos comuns de negros como caipiras analfabetos.
} 
por sua suposta inteligência no ringue, reproduzindo a histórica tendência de elogiar atletas brancos por serem mais inteligentes que os negros.

A imprensa em geral anunciou que a derrota de Louis foi sentida somente por negros. Um escritor fez a seguinte piada política sobre o combate: "A Itália mandou milhares para conquistar a Etiópia. Um nazista só foi suficiente para conquistar o Harlem". ${ }^{37}$ Harlem e outras comunidades negras dos Estados Unidos foram tratadas como se fossem colônias ou entidades completamente separadas do país. Joe Louis representava essas comunidades apenas, enquanto o estrangeiro da nação nazista representava os Estados Unidos pela confirmação da supremacia branca e da lógica do nacionalismo excludente.

Como o próprio Louis percebeu, os negros norte-americanos defenderam seu herói. ${ }^{38}$ Comunidades negras em toda parte do país ficaram devastadas pela derrota de Louis, e, em choque, rumores emergiram e foram fundamentados por alguns membros da imprensa negra. O popular jornal afro-americano Pittsburgh Courier, por exemplo, publicou:

O Joe Louis que entrou no ringue (...) absolutamente não era o Louis que a gente conhece. Dizemos que Joe Louis foi drogado. Claro que não temos fatos nem evidências (...) (mas) existiu alguma coisa que derrubou Joe Louis que não estava contido nas luvas de boxe de Max Schmeling. ${ }^{39}$

Igualmente, outro artigo, intitulado "Rumores bárbaros atingiram o Harlem depois da luta: Todos refutados", também aponta que as comunidades negras tinham consciência de Louis ser herói da raça em lugar de símbolo nacional..$^{40}$ Essa consciência ajudou a disseminar e dar verossimilhança às falsas acusações de que brancos tivessem manobrado para sabotar a luta de modo a resguardar a ideologia da supremacia branca.

${ }_{37}$ Philadelphia Evening Public Ledger, 20 de junho de 1936, Joe Louis Scrapbooks. "Italy sent thousands to conquer Ethiopia. One Nazi was enough to take Harlem." (Tradução da autora.) Pollock também referiu-se ao combate de Louis contra o ex-campeão italiano Primo Carnera em junho de 1935 em Nova York, no qual Joe Louis derrotou Carnera. A luta aconteceu meses antes de a Itália invadir a Etiópia e foi considerada, tanto por negros como por brancos, como uma representação da guerra iminente. Ver Graham, "Hitler's Nazism, Sport, and Joe Louis".

${ }^{38}$ Joe Louis com Edna e Art Rust, Jr., Joe Louis: My Life, Hopewell, The Ecco Press, 1978, p. 91.

${ }^{39}$ Pittsburgh Courier, 27 de junho de 1936. "The Joe Louis that walked into the ring (...) was positively not the Joe Louis that we have known: We say (...) that Joe Louis was doped. Of course, we have no facts or evidence on it, (but) there was something that defeated Joe Louis that was not contained in Max Schmeling's boxing gloves." (Tradução da autora.)

${ }^{40}$ Idem. "Wild Rumors Hit Harlem Following Fight: All Disproved." (Tradução da autora.) 
No combate Louis-Schmeling em 1936, o segmento dominante branco da sociedade norte-americana, sem medo de validar a ideologia nazista, excluiu flagrantemente os negros da comunidade nacional, sustentando a supremacia branca como base do nacionalismo norte-americano.

No entanto, apenas dois anos depois, Louis, agora campeão mundial, enfrentaria Schmeling mais uma vez - e nesse combate, a atitude do público mudou completamente. ${ }^{41}$

\section{Joe Louis: negro americano}

Vários eventos importantíssimos aconteceram na Europa entre os dois combates de Joe Louis contra Max Schmeling. Em 1938, Hitler alcançou popularidade sem precedentes, a Alemanha avançara sobre a Áustria, deixando claras as intenções alemãs de expansão. ${ }^{42}$ Além disso, todos os dias a mídia transmitia reportagens sobre a violência na Europa e na Ásia. Manchetes como "Campanha de terror judeu se espalha" e "Goebbels avisa que os judeus precisam ir embora: Diz que a lei os levará a sair de Berlim 'em breve"” se tornaram bastante comuns nos meses que antecederam ao combate. ${ }^{43}$ Mesmo que, àquela altura, a posição do governo norte-americano fosse a de neutralidade, muitos norte-americanos, principalmente judeus e aqueles com famílias na Europa, sentiam os horrores do nazismo pessoalmente. ${ }^{44} \mathrm{O}$ fascismo tinha se transformado em uma ameaça internacional aos chamados governos democráticos, e chegara a hora em que os brancos norte-americanos não poderiam mais priorizar ideologicamente a supremacia branca sobre os verdadeiros valores da democracia.

Quando Max Schmeling desembarcou do S.S. Bremen em Nova Iorque, em 1936, encontrou uma das maiores multidões a receber um pugilista estrangeiro. Quando desceu do Bremen dois anos depois, viu uma multidão até

\footnotetext{
${ }^{41}$ Em 1937, Joe Louis conquistou o título de Jimmy Braddock, sendo o primeiro negro a ter oportunidade de lutar num combate pelo título desde Jack Johnson. Como Jack Johnson, Louis enfrentou muitos obstáculos para obter essa oportunidade. No final, foram incentivos financeiros que levaram Braddock a aceitar a luta contra Louis. Mike Jacobs, promotor das lutas de Louis, por exemplo, ofereceu a Braddock 10\% dos lucros que ganharia nos combates de Louis pelo resto da carreira de Louis. Ver Louis et al., My Life, p. 105-107.

${ }^{42}$ Schmeling, Max Schmeling, p. 151.

${ }^{43}$ Los Angeles Times, 19 de junho de 1938; New York Times, 22 de junho de 1938.

${ }^{44}$ Sammons, Beyond the Ring, p. 114.
} 
maior, mas esse grupo não foi cordial. ${ }^{45}$ Nesse momento, Schmeling percebeu que a opinião pública tinha mudado, dessa vez, contra ele:

Quando o Bremen encostou no porto de Nova Iorque, havia pessoas berrando e levando placas (...) Manifestantes (também) marchavam de trás para a frente diante do meu hotel carregando placas com as palavras "BOICOTEM O NAZISTA SCHMELING!" Quando fui às avenidas Broadway ou Fifth, pessoas paravam e me zombavam com o braço levantado (no estilo nazista)... Até o dia da luta recebi milhares de cartas odiosas assinadas "Heil Hitler" ou "Bata no Hitler". Eu não sabia o que fazer - apenas dois anos antes essa mesma cidade tinha torcido por mim com todo entusiasmo. ${ }^{46}$

Schmeling sempre afirmou que nunca fora nazista, nem defensor do regime de Hitler. Embora existissem artigos com declarações dele de teor racista sobre a luta contra Joe Louis, Louis e Schmeling insistiram que Schmeling não havia feito aqueles comentários. ${ }^{47}$ Apesar disso, os norte-americanos acreditaram que ele não apenas era nazista de coração, mas poderoso no regime de Hitler.

O jornalista Westbrook Pegler ofereceu uma explicação com base em novos dados para a nova reação do público norte-americano a Schmeling:

A diferença no presente caso é que Schmeling passou a ser utilizado oficialmente por Adolf Hitler e Goebbels, o Ministro de Propaganda do Estado (...) somente depois de ele ter derrotado Louis em Nova Iorque. Até aquele momento eles o ignoraram...

Quando Schmeling veio lutar contra o Louis (...) O próprio Herr Hitler (achou) que Schmeling ia ser vencido de modo acachapante (...) Hitler e Goebbels não queriam nada com um homem que (...) aparentemente ia ser derrotado por um negro, e assim não o reconheceram (oficialmente) até receberem os resultados. Hitler e Goebbels (...) aprenderam que Schmeling era um exemplo nobre para a mocidade nazista e foi utilizado oficialmente pelos políticos de Berlim. ${ }^{48}$

Pegler tem razão sobre a utilização ideológica de Max Schmeling pelo governo nazista depois da primeira luta. No dia em que Schmeling voltou a Berlim depois de nocautear Louis, recebeu um convite para visitar Hitler. Schmeling escreveu: "Hitler se aproximou e de uma maneira formal (...) ex-

\footnotetext{
${ }^{45}$ New York Daily Mirror, 22 de abril de 1936, Joe Louis Scrapbooks.

${ }^{46}$ Schmeling, Max Schmeling, p. 151-152.

${ }^{47}$ Louis et al., My Life, p. 124-125.

${ }^{48}$ Chicago Daily News, 23 de junho de 1937, Joe Louis Scrapbooks.
} 
primiu a gratidão dele e do povo alemão". Além disso, depois de assistir ao filme da luta, Hitler decidiu que devia ser usado na campanha propagandística. Schmeling lembrou:

(Hitler falou): "Esse filme vai ser mostrado (...) por todo o país!” (...) Goebbels designou (...) ao diretor Zerlett a tarefa de transformar o filme em documentário. O filme foi lançado com o título A Vitória de Max Schmeling - Uma Vitória Alemã e foi exibido em todos os cinemas por semanas. ${ }^{49}$

A caracterização do nocaute de Joe Louis por Schmeling pelo governo de Hitler como "vitória alemã" contribuiu para transformar Schmeling em um autêntico nazista na perspectiva dos norte-americanos.

A despeito da oposição a Schmeling ter crescido, por conta de sua raça ou nacionalidade, muitos nos Estados Unidos continuavam a acreditar que ele repetiria a vitória de 1936. A maioria dos especialistas acreditava que Louis manteria o título de peso pesado e, de acordo com uma pesquisa, $60 \%$ dos especialistas em boxe esperaram que Louis vencesse. ${ }^{50}$ Mas entre os $40 \%$ que apostaram em Schmeling, o racismo era evidente. O popular ex-campeão Jack Dempsey, por exemplo, continuou a prever a vitória do oponente branco de Louis, contrariando previsões da maioria dos especialistas. Aliás, ele continuou afirmando que o negro era forte, porém estúpido, e que o branco era inteligentíssimo. Em artigo, Dempsey discordou dos peritos que afirmavam que Schmeling tinha vantagem sobre Louis por causa do nocaute em 1936, argumentando: "Não acho que o Louis entende o significado do medo. É preciso ter imaginação para ter medo. O Louis não tem imaginação. (Tem) apenas dois punhos".

Dempsey concluiu com a previsão de que Louis não fosse conseguir evitar fazer "aquilo que Schmeling, mais inteligente, quer que ele faça". ${ }^{51}$ Embora Louis fosse campeão peso pesado mundial, embora já tivesse um recorde extremamente impressionante, Dempsey e vários outros não conseguiram abandonar o que foi instintivo para eles - a idéia da superioridade da raça branca.

${ }^{49}$ Schmeling, Max Schmeling, p. 129-130.

${ }^{50}$ Buffalo Evening News, 21 de junho de 1938, Joe Louis Scrapbooks.

${ }^{51}$ This Week Magazine no Los Angeles Times, 19 de junho de 1938. O Dempsey disse: "I don't think Louis knows what fear means. You must have imagination to have fear. Louis has no imagination. Just two fists"; e "Louis is going to fall right in and do what the smarter Schmeling wants him to do". Dempsey também tinha lançado uma campanha para achar outra "grande esperança branca" no início da carreira de Louis. 
Tais vozes que apoiaram Schmeling, como foi o caso de Dempsey, estavam aparentemente em minoria, pelo menos em público. Mais comuns eram aquelas pessoas que se esforçavam por despolitizar a luta. A leitora Myrtle Weigand exprimiu a sua decepção pela "falta do espírito esportivo" que o público norte-americano demonstrara em relação a Schmeling. Defendia que a política deveria ser afastada dos esportes. Mas, nas suas exaltadas súplicas para despolitizar a luta em nome do patriotismo fiador do espírito esportivo, termina sua carta ao jornal com as seguintes palavras: "Desejos sinceros que a América fique com o título". ${ }^{52}$ Assim, até pessoas que criticavam a politização do combate em nome do patriotismo não conseguiram evitar a realidade fundamental: nessa luta, Joe Louis era a América. Provavelmente Weigand, assim como outros norte-americanos, não colocava em discussão a americanidade de Louis, visto que ele nascera nos Estados Unidos, nem a percebiam como uma questão política. Mas a história dos negros norte-americanos, inclusive nesse contexto do boxe peso pesado, mostra que simplesmente aceitar Louis como representante dos Estados Unidos era, em si mesmo, um ato político.

Muitos observadores expressaram sua intolerância em relação a pessoas como Weigman, que não foram capazes de apreender o significado político da luta. Um leitor frustrado criticou representantes da mídia que não reconhecia as repercussões da luta Louis-Schmeling:

Como é que a gente pode divorciar o esporte da política nesse caso em que Schmeling tem provado, pelos seus comentários e atitudes, que é parte do regime nazista? Quando (...) será que a imprensa americana atentará aos fatos? Quando a imprensa de esporte perceberá que está tratando com alguém cujo sucesso prolongado reforçará tudo o que há de mau na civilização mundial?

Como é que (...) um americano que adora a liberdade, consegue se manter tão iludido a ponto de acreditar que Schmeling é apenas mais outro pugilista (...) quando realmente é um líder potencial para aquelas forças de destruição do mundo que os americanos nunca aceitarão? ${ }^{53}$

O efeito simbólico do encontro de Louis-Schmeling em 1938 foi duplo. Se Max Schmeling era o vilão antidemocrático, os Estados Unidos precisavam de um herói pró-democrático para os defender e representar, e Joe Louis seria o homem incumbido de carregar o país nos seus ombros. Enquanto Schmeling

${ }^{52}$ New York Times, 18 de junho de 1938, Joe Louis Scrapbooks.

${ }^{53}$ Hartford Daily Courant, 21 de junho de 1938, Joe Louis Scrapbooks. 
era crescentemente percebido como uma versão pugilista de Adolf Hitler, para os norte-americanos Joe Louis progressivamente se tornava a personificação da grandeza democrática norte-americana. Pela primeira vez no território dos Estados Unidos, um homem negro foi transformado em símbolo da democracia norte-americana. ${ }^{54}$ Joe Louis não mais lutava somente para o Harlem e outras comunidades afro-americanas no país, nem a população negra foi o único segmento da sociedade a depositar nele suas esperanças. Em 1938, Louis finalmente foi considerado americano, ou como Maynard Jackson lembrou: "Louis não foi um herói para os negros, mas o primeiro herói nacional legítimo que por acaso era negro". ${ }^{5}$

Políticos norte-americanos também compartilharam esse sentido simbólico da segunda luta Louis-Schmeling e não queriam que o título ficasse com a Alemanha nazista. O próprio presidente Franklin D. Roosevelt convidou Louis para jantar antes do combate. Conforme Louis, durante a visita, Roosevelt pediu para apalpar os músculos dele, dizendo: "Joe, a América está dependendo desses músculos”. Tais palavras do próprio presidente afetaram Louis fortemente. Ele percebeu que os Estados Unidos esperavam que ele aniquilasse Schmeling para se sentirem invencíveis diante de qualquer ataque que os nazistas tentassem dirigir contra os Estados Unidos e seus aliados. ${ }^{56}$

Max Schmeling tinha consciência do papel que o público norte-americano havia atribuído naquele momento a Louis. Schmeling escreveu:

Joe Louis, que ontem tinha sido celebrado pelo Harlem como herói da classe baixa, de repente foi transformado em símbolo da liberdade e igualdade para todo povo e toda raça contra a ameaça Nazista. Logo eu estaria ouvindo que pessoas tinham convencido Louis que com essa luta eu esperava provar a superioridade dos brancos sobre os negros. Joe, o homem negro, se viu no papel inesperado de herói nacional para todos americanos. ${ }^{57}$

\footnotetext{
${ }^{54}$ A expressão "no território dos Estados Unidos" é uma especificação importante, porque Jesse Owens e outros atletas negros representaram a democracia americana nos Jogos Olímpicos de 1936. Ironicamente, no mesmo ano que esses atletas eram aplaudidos por seu sucesso na Alemanha, Max Schmeling ia ser louvado por nocautear Joe Louis nos Estados Unidos. Possivelmente, os Jogos Olímpicos de 1936 foram um evento mais facilmente associado a Hitler do que a luta, no mesmo ano, por terem os Jogos Olímpicos se realizado na Alemanha, com a presença do próprio Hitler.

${ }^{55}$ Joe Louis Barrow, Jr., e Barbara Munder, Joe Louis: 50 Years an American Hero, New York, McGraw-Hill Book Company, 1988, p. 12.

${ }^{56}$ Louis et al., My Life, p. 137. Louis lembrou que Roosevelt dissera: "Joe, we're depending on those muscles for America". (Tradução da autora.)

${ }^{57}$ Schmeling, Max Schmeling, p. 152.
} 
No dia 22 de junho de 1938, na segunda maior platéia na história do boxe, 75 mil torcedores foram ao Yankee Stadium assistir ao desenlace do drama. ${ }^{58}$ Schmeling documentou:

Doc Casey, que tinha estado no meu canto tantas vezes, não estava lá. A histeria geral e a inundação de cartas ameaçadoras o tinham chocado e apavorado. Nunca me senti tão sozinho antes de um combate.

Protegido por uma parede de policiais, entrei no estádio. Quando fiquei visível à multidão, uma explosão de desordem completa ocorreu. Claro que houve alguns aplausos também (...) mas os outros gritos quase os extinguiram (...) Mesmo flanqueado por 25 policiais, eu ainda fui atingido por pontas de cigarros, cascas de bananas e copos descartáveis, e tive que colocar uma toalha sobre a minha cabeça só para chegar ao ringue (...) Quando chegamos ao ringue, a polícia o cercou. Ficaram de pé encarando a platéia, servindo como escudo aos objetos jogados. ${ }^{59}$

Quando Joe Louis iniciou sua caminhada até o ringue, as saudações aumentaram e continuaram por minutos depois de pisar no ringue. ${ }^{60}$ No momento em que o sino tocou, Louis foi direto em direção a Schmeling e desferiu vários socos imediatamente. Schmeling caiu nas cordas e no chão várias vezes até o árbitro Arthur Donovan suspender a luta. Foram somente 124 segundos no primeiro round. ${ }^{61}$ A platéia entrou em delírio - a democracia tinha triunfado sobre o nazismo.

Depois da luta, Joe Louis declarou que, para o mundo, a derrota de Schmeling profetizava a ruína da Alemanha nazista. Jornalistas por todo o país concordaram, inclusive Ted Carroll, que escreveu:

O colapso completo da teoria começou com Jesse Owens nos Jogos Olímpicos de 1936, em Berlim, e alcançou o ápice naquele ringue do Yankee Stadium (...) levando os discípulos de tais credos a refletir profundamente. ${ }^{62}$

Na realidade, a Alemanha estava na defensiva mesmo depois da luta. O regime nazista esforçou-se muito para minimizar os efeitos do resultado embaraçoso do combate. O governo chegou a interromper a transmissão da luta quando a derrota de Schmeling era iminente. Louis declarou que o regime não

\footnotetext{
${ }^{58}$ Barrow, Jr. e Munder, Joe Louis, p. 7. O número de torcedores no Yankee Stadium foi documentado na autobiografia de Schmeling, p. 152.

${ }^{59}$ Schmeling, Max Schmeling, p. 153.

${ }^{60}$ Margery Miller, Joe Louis: American, Nova York, A. A. Wyn, 1945, p. 105.

${ }^{61}$ Idem, p. 142-143.

${ }^{62}$ The Ring, junho de 1938, Joe Louis Scrapbooks.
} 
queria que o povo alemão soubesse que um simples nigger estava golpeando a raça ariana. ${ }^{63}$ Joseph Goebbels fez circular rumores de que Louis dera um soco ilegal de propósito e que colocara chumbo nas ataduras da mão. Schmeling entendeu que tais alegações assinalavam que ele não tinha mais um lugar na política alemã, na condição de celebridade instrumentalizada pelo Estado.

É possível que Max Schmeling tenha acreditado que o seu primeiro combate contra Louis fora uma pura competição esportiva, completamente dissociada da política, mas ele estava enganado. Schmeling e a maioria dos seus contemporâneos brancos não perceberam que o mesmo fator que lhe rendera tantas aclamações do público norte-americano em 1936 também produziu o repúdio público a ele em 1938 - o patriotismo americano. A identidade, o sentimento nacional tinha mudado rapidamente, de um paradigma excludente racialmente, no qual Schmeling era o representante mais adequado da grandeza dos Estados Unidos, para uma ideologia mais inclusiva racialmente, em que o negro Joe Louis passara a emblema da democracia norte-americana.

Apesar da mudança favorável à ideologia inclusiva, séculos de nacionalismo racista não se extinguiram em apenas dois anos. Embora a ideologia de inclusão racial, ou seja, a democracia racial nascente, ganhasse terreno, o comportamento de brancos em relação aos negros não deixava de refletir os ideais da supremacia branca. Como a escritora negra Maya Angelou lembrou, um homem negro e a sua família não podiam ser vistos por um branco numa rua vazia depois de Joe Louis provar que "a gente era o povo mais forte no mundo". ${ }^{64} \mathrm{O}$ próprio Joe Louis também observou a discrepância entre as ações e palavras dos brancos norte-americanos. De acordo com ele: "Brancos americanos - enquanto alguns deles linchavam negros no sul do país, me pediam para nocautear a Alemanha". ${ }^{65}$ Além disso, as leis e políticas dos Estados Unidos continuaram a sustentar o racismo por toda a nação, embora o ímpeto para desmantelá-lo efetivamente começasse logo depois. A comunidade negra que incitou esse ímpeto enfrentou resistência fortíssima na sociedade e no governo norte-americano, mesmo depois da ideologia de democracia racial ganhar espaços.

\footnotetext{
${ }^{63}$ Miller, Joe Louis, p. 143-144. Louis disse: "They didn't want their people to know that just a plain old nigger was knocking the shit out of the Aryan race". (Tradução da autora.)

${ }^{64}$ Harry Edwards, Sociology of Sport, Homewood, Illinois, Dorsey Press, 1973, p. 257. (Tradução da autora.)

${ }^{65}$ Louis et al., p. 137.
} 
No seu livro The racial contract (O contrato racial), o filósofo Charles Mills lança luz sobre a disparidade entre ideologia e comportamento nos Estados Unidos durante a transição para a democracia racial. Numa revisão do tradicional sentido de contrato social em Locke, Hobbes, Kant e Rousseau, Mills estabelece a raça como elemento basilar sobre o qual a "civilização" foi fundada, e define a supremacia branca como um sistema político que deu origem ao mundo moderno que existe. ${ }^{66}$ Embora o "contrato social" original esteja presumivelmente "empenhado em alcançar igualitarismo moral, a igualdade de todo homem, a noção que os interesses de todo homem importam igualmente e que todo homem deve ter direitos iguais", a história da escravidão e da opressão racial na civilização ocidental indicam que sempre houve um contrato racial. ${ }^{67}$ No contrato racial, a igualdade é reservada apenas aos brancos. Não-brancos "nascem sem liberdade nem igualdade", enquanto brancos devem consentir em ocupar a posição superior na hierarquia racial, mesmo que esse consentimento nem sempre seja dado conscientemente. ${ }^{68}$ Os Estados Unidos historicamente têm adotado a ordem estratificada do contrato racial, e, por conseguinte, faz sentido a ligação entre nacionalismo norte-americano e racismo.

Se o contrato racial era um elemento estruturante da sociedade norteamericana, estando racismo e nacionalismo tão interligados, como é que em 1938 brancos norte-americanos puderam deixar de lado, em nome do patriotismo, seus irmãos alemães em favor de um afro-americano? Até mais intrigante, como é que esse peso pesado negro chegou a representar os Estados Unidos? Segundo Mills, os nazistas quebraram o contrato com a perseguição aos judeus, porque estes, mesmo não sendo considerados inteiramente brancos, ainda eram vistos como "europeus fronteiriços, brancos com um ponto de interrogação" ou "branco-sujos". ${ }^{69}$

"Branco-sujos" situam-se na camada inferior da categoria geral "branca". Muitos "branco-sujos", tais como judeus e irlandeses, tinham sido vítimas do racismo intra-europeu. Todavia, na década de 1930, não era mais condizente com o contrato racial oprimir os brancos-sujos tão gravemente como os nãobrancos. Para a comunidade branca internacional, o tratamento dos judeus

\footnotetext{
${ }^{66}$ Charles W. Mills, The Racial Contract, Ithaca, Londres, Cornell University Press, 1997, p. 1. ${ }^{67}$ Idem, p. 16.

${ }^{68}$ Idem. Mills argumenta que os judeus são "borderline Europeans, white people with a question mark" ou "off-whites".

${ }^{69}$ Idem, p. 79.
} 
como se fossem não-brancos remetia a épocas já passadas, representando "uma versão do contrato racial mais excludente do que poderia ser aceito naquela época”. Os nazistas violaram o contrato por oprimir um grupo que, embora fosse "branco-sujo", ainda devia ser incluído "no clube da brancura" ${ }^{70}$ Essa violação nazista do contrato racial produziu um desconforto muito grande diante da dúvida sobre quais brancos seriam vulneráveis à perseguição, tirando a segurança assegurada a todos os brancos pelo contrato.

Hitler mesmo apontou que sua política de supremacia branca era a mesma que os norte-americanos tinham usado para colonizar o continente norte-americano e retirar dos não-brancos o status humano, como ele fazia com os judeus. ${ }^{71}$ As próprias nações que acusaram Hitler de ser a encarnação do mal, na verdade tinham preparado o caminho para sua política racista, e embora Hitler assim afirmasse, outros países do Oeste não queriam reconhecêlo. Mills cita Conrad, ao dizer:

Auschwitz foi a implementação industrial moderna de uma política de extermínio que já tinha sustentado o domínio mundial europeu por um grande tempo (...) E quando o que tinha sido feito no coração das trevas foi repetido no coração da Europa, ninguém o reconheceu. Ninguem queria confessar o que todos já sabiam. ${ }^{72}$

A política violenta de Hitler no coração da Europa e a quebra do contrato racial fizeram com que milhões de brancos percebessem que o racismo era antagônico a uma efetiva democracia. O nazismo, considerado antidemocrático, fez da raça (ou a igualdade entre elas) um elemento mais visível na democracia. Hitler pôs em questão, diretamente e indiretamente, a chamada democracia dos países do ocidente. Esse clima na política internacional exigiu que "a sociedade branca interrogasse a sua própria integridade moral". ${ }^{73}$ Mas os norte-americanos brancos estavam mais interessados em apresentar seu país como uma democracia racial do que em consentir na erradicação efetiva do racismo em sua sociedade.

\footnotetext{
${ }^{70}$ Idem, p. 104.

${ }^{71}$ Idem, p. 106.

${ }^{72}$ Idem, p. 105. "Auschwitz was the modern industrial application of a policy of extermination on which European world domination had long since rested (...) And when what had been done in the heart of darkness was repeated in the heart of Europe, no one recognized it. No one wished to admit what everyone knew." (Tradução da autora.)

${ }^{73}$ Dominic Capeci, Jr. e Martha Wilkerson, "Multifarious Hero: Joe Louis, American Society and Race Relations During World Crisis, 1935-1945”, no Journal of Sport History 10.3 (Inverno, 1983), p. 10.
} 
Joe Louis adequava-se ao sonho da sociedade norte-americana branca. Um peso pesado afro-americano que tinha um soco poderoso, mas não parecia contestar a hegemonia branca, o transformava num representante ideal e seguro da nova ideologia nacionalista de democracia racial. Ao transformar Louis em representante do país e herói nacional, os Estados Unidos ficaram mais próximos da imagem da terra de liberdade e democracia que precisavam difundir nessa época tão incerta. A conduta pessoal íntegra de Louis, que não provocava os brancos, também favoreceu a emergência dessa nova ideologia da democracia racial "sem que as condições básicas de vida dos negros norteamericanos fossem questionadas" ${ }^{74}$ Louis transformou-se em "prova viva" de que os Estados Unidos realmente eram um modelo de sociedade democrática, de igualdade de oportunidades e tolerância, uma democracia racial, em tudo oposta ao ódio racista alemão. Quando os nazistas e outros apontavam a hipocrisia racial americana, brancos nos Estados Unidos podiam valer-se da celebridade e popularidade de Louis como "evidência" da ausência de preconceito e intolerância em seu país. Desta maneira, a popularidade de Joe Louis e sua ascensão rápida à condição de ícone democrático foi, em grande parte, decorrência do fato de ser negro. A cor de Louis funcionou como uma salvaguarda psicológica para o país, livrando a América branca da necessidade de enfrentar a existência do racismo na sua sociedade. Assim, o imaginário construído em torno de Joe Louis refletia tudo aquilo que os Estados Unidos fingiam ser.

\footnotetext{
${ }^{74}$ Idem, p. 10-11. “(...) without challenging the basic conditions of black life”. (Tradução da autora.)
} 